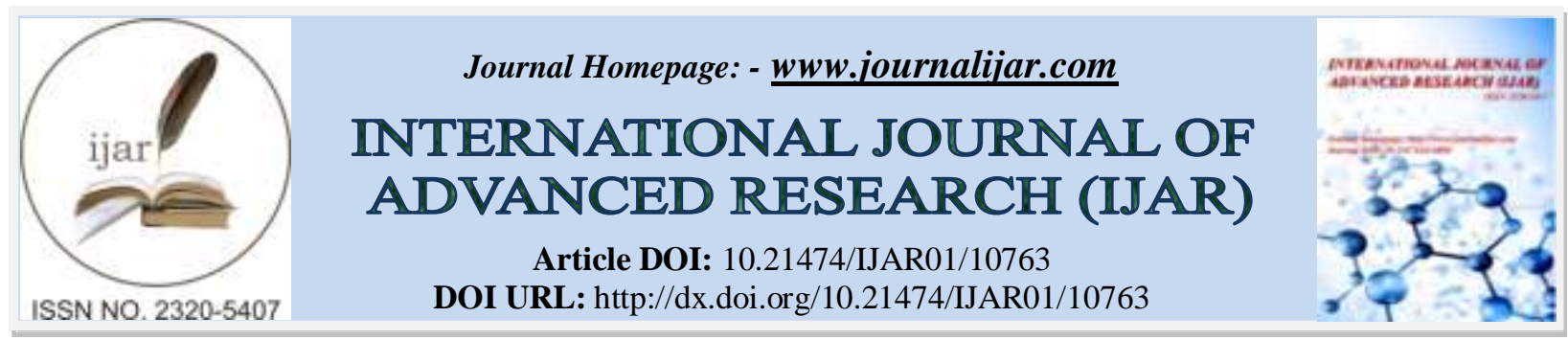

RESEARCH ARTICLE

\title{
THE EFFECTS OF CATTLE RUSTLLING IN WEST POKOT COUNTY: A CASE OF KACHELIBA CONSTITUENCY
}

\author{
Andrew Pchumba \\ Ma (Public Policy And Administration) Northwestern Christian University Risper Konzolo Ma (Public Policy And \\ Management).
}

\section{Manuscript Info}

.1........................

Manuscript History

Received: 07 February 2020

Final Accepted: 10 March 2020

Published: April 2020

Key words:-

Crime, Deviant, Marginalization,

Organic Inferiority, Primitiveness

\section{Abstract}

Violent Crime has been in place throughout time in memorial. It has been so troublesome and so persistent in marginalized areas like West Pokot, Baringo, Turkana counties etc that much efforts has been devoted to understanding its root causes. However, much has been unattended and eventually MARGINALIZATION is currently prevailing as the key root cause. Modern day approaches to deviant and criminal behavior can be divided into the general categories of sociological, biological and psychological theoretical explanations. "Scientific" explanations for deviant and criminal behavior centered on the importance of inherited factors and generated the importance of environmental influences. "Deviant" individuals are born, not made. Cesare Lombroso (1835-1901), was an Italian doctor who believed that too much emphasis was being put on "free will" as an explanation for deviant behavior which leads to LIVESTOCK THEFT. While trying to discover the causes and differences between deviant and deviant inhabitants resulting to practicing cattle rustling, he concluded that it was to understand the insights of the root causes. When he studied some of the insights, he came with the issue of Criminality in the communities practiced by people with certain characteristics' of certain facial physique. At the sight of that skull, I seemed to see all of a sudden, lighted up as a vast plain under a flaming sky, the problem of the nature of the criminal-an atavistic being who reproduces in his person the ferocious instincts of primitive humanity and the inferior animals. (Taylor et al., 1973, p. 4) According to Lombroso, criminals are evolutionary throw backs whose behavior is more apelike than human. They are driven by their instincts to engage in deviant behavior. These people can be identified by certain physical signs that betray their savage nature. Lombroso spent much of his life studying and dissecting dead prisoners in Italy's jails and concluded that their criminality was associated with an animal-like body type that revealed an inherited primitiveness (Lombroso-Ferrero, 1972). He also believed that certain criminal types could be identified by their head size, facial characteristics (size and shape of the nose, for instance), and even hair color, His writings were met with heated criticism from scholars who pointed out that perfectly normal-looking people have committed violent acts. (Modern social scientists would add that by confining his 
research to the study of prison inmates, Lombroso used a biased sample, thereby limiting the validity of his investigations.) Shortly before World War II, anthropologist E. A. Hooten argued that the born criminal was a scientific reality. Hooten believed crime was not the product of social conditions but the outgrowth of "organic inferiority.

Copy Right, IJAR, 2020,. All rights reserved.

\section{Introduction:-}

This chapter discusses background of the study, statement of the problem, research objectives, and research questions, significance of the study scope and limitation of the study and the conceptual framework.

\section{Background to the study:}

Schools of criminology give the signs of criminal behavior and pride as the results of cattle rustling, (Paul vi, 1969) reveals that there are increasing acts of stock theft, deterioration of Peace and slow growth of development as results of cattle rustling menace. His Excellency the President asserted that "Security is a shared mandate of all people living in Kenya. The First rule of Security is vigilance... we must all embrace Nyumba Kumi" This has prompted the Government to form Anti Stock Unit a special wing of the Kenya Police.

McGoldrick and carter (1998) observed that community pride has a significant impact on the coexistence of respective communities which require harmony and the significance of others. Joseph kaguthi (1985) Kenya's Nyumba Kumi founder clarified that cattle rustling menace affects general economic lifestyles thereby retarding development. The menace eventually makes the respective communities arm themselves using illegal fire arms for social defence in reference to the occasional attacks. Countries like Uganda which had had war sometimes had had their small weapons infiltrate into our countrythat is now causing instability in the whole County that require government intervention. The target ends up cattle rustling areas causing instability in every aspect of life name it; Education, economy etc.

However, $95 \%$ of them menace could be done away with incase the so called Equalization fund could be availed to respective communities. The fund besides what the national Government has budgeted was to mean to bring at par the communities which were left behind due to some marginalization which dates back to colonial era. Of course, the National Government is serious on this and it has disbursing the money to respective deserving communities. In the process of this event, we expect much of the said problem escalating cattle rustling to be minimized and eventually get diminished.

\section{Problem statement:}

Violent Crimes seems to be rendering the West Pokot Community poor and poorer causing instability to the Society thereby inhibiting development agendas. Every individual and respective community is wondering how this element of criminal activities can be eliminated and how they themselves can dissociate from violent crimes to maintain stability in the respective community and sustain a healthy co-existence. Leaders need to first establish healthy, intellectual, emotional and physical boundaries with every community staying in harmony with each other. Cattle rustling Menace is quiet well known to retard developmental agendas but nobody seems to be questioning about it. Developments in an area or community can only come when there is peace and community stability. This has instigated the researcher to find out why such a community is exposed to cattle rustling rendering the less fortunate community poor. Thus it is the duty of every Citizen to embrace methods geared to maintaining peace as such. It is evident that the communities that have embraced peace since independence have prospered to greater heights more than those that have engaged cattle rustling activities.

\section{Objectives of the Study:-}

The research is aimed to:-

i. To establish the factors influencing Cattle rustling activities in West Pokot County.

ii. To establish deviant factors influencing underdevelopment emanating from cattle rustling in West Pokot County. iii. To determine challenges facing communities practicing cattle rustling activities in West Pokot County. 


\section{Research questions:}

i. What are the key factors causing Cattle rustling activities in West Pokot County?

ii. What are the deviant factors that influencing underdevelopment emanating from cattle rustling in West Pokot County?

iii. What challenges face communities that practice cattle rustling in West Pokot County?

\section{Significance to the study:}

Currently, there is high rate of violent crimes resulting to disharmony, disunity, and lack of peace in Pastoralist communities. This study therefore will attempt to empirically examine the causes of community issues influencing stability in Peace on people living in nomadic setting. The hope that the result arrived at my applicable to the wider community and will help prove as a useful research for everyone and those interested in improving their respective communities and its welfare and their role in Nation building. The study will assist the future scholars to come up with ways and means of informing the government on the process to follow to curb the cattle rustling menace. The research will contribute some essential ideas that will be utilized by the futer researchers in addition to whatever might have been contributed in the study. The study will inform the ministry of interior and coordination of national security in Kenya the challenges that Westpokot community face. This way, policy makers are expected to come up with new policies and rules that would improve the living standards of the offenders and too for the whole society and obtain measures that should be enforced to curb the Cattle rustling menace. The study on this Violent Crime type of Crime will eventually help the government come up with ideal steps to curb the menace. This will help the law enforcers concentrate on other areas that infiltrate the cattle rustlers and cause some community stability. Upon the success of eradicating the menace, the Government will also be in a position to channel the resources that have been perennially directed to curb the menace to other useful developmental agendas.

\section{Scope and limitation of the study:}

The research study was done at Kacheliba area of West Pokot County. The area was chosen because the people living there have been practicing cattle rustling since time inmemorial. Even after Kenya attained and celebrated 50 years of Independence, the menace is still prevalent. The study entirely focused on factors that influence instability in cattle rustling regions to enable the researcher explains its effects on community issues. The study did not involve teenagers below 18 outside Kacheliba area of West Pokot County. The purpose was to generate appropriately desired results.

\section{Conceptual Framework: \\ Independent Variable:}

\begin{tabular}{|l} 
Social and Economic factors \\
- Poverty \\
- Income \\
- Living Standards \\
- Religion \\
- Financial influence \\
- Illiteracy \\
- Poor infrastructure \\
- Cultural
\end{tabular}

Dependent Variable

Cattle rustling menace

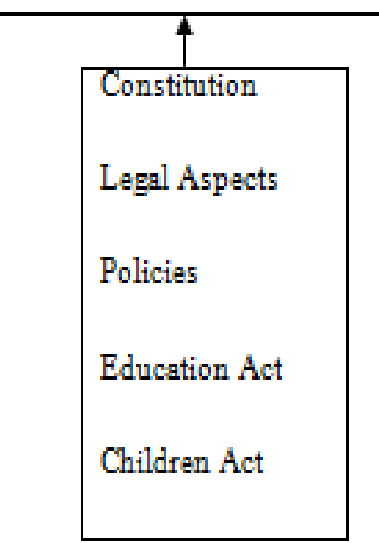

Intervening Variables 


\title{
Introduction:
}

This chapter reviews literature done by other scholars contributing factors to cattle rustling in pastoral communities and particularly Pokot community.

The literature review in this chapter was focused on what professional way of solving the menace, psychologists, and other techniques applied by the Community e.g. Kangaroo Courts may need to understand first about the cattle rustling menace in order to design contextualized interventions for reinforcing Government policies to curb the menace. Additionally this chapter includes categorized terms of tactical considerations and suggestions for that have been cited or deduced by the researcher from the literature that is related to the purpose of this study. A cattle rustling in it is an evil practice thus the approach from criminal point of view should be steady to enable successful outcome of the Research.

\begin{abstract}
Allegory applied to cattle rustling:
Retired Kenyan armed Forces General (General Tonje 2002) pointed out lack of schools and other social amenities to the marginalized communities as a predicament to cattle rustling menace. If generally the former governments had done equitable developments across the country of Kenya, such menaces would have not been experienced. Altogether, it is not too late for the current Government administration to act. They have already started with allocating equalization funds which are set aside in every annual financial budget to assist in alleviating poverty in the marginalized areas. This is a key thing that the recent heads of state have thought of but done nothing. We hope it will bring the desired changes that eradicate the menace of cattle rustling. If in any case some case studies which have been obtained while handling elements of court procedures would have been followed to the latter, then some of the issues related to the menace would have been attended to and addressed well.
\end{abstract}

\section{Contributing factors to cattle rustling Menace:}

Minuchin and Nicholas (1993) emphasized that the failure to identify and resolve the contributing factors (possible causes) for instance cattle rustling creates serious consequences, because the menace usually re-enact the dynamics of deteriorations in peace and instability in their second or subsequent generations (Ganong \& Coleman, 1989; Gottman, 1994b).

Clinical finding in reference to some of the causes of cattle rustling is $95 \%$ of behavioral and lack of in-depth civilization as the main contributing factors of cattle rustling (Berger, 1998; Gottman, notaries, Gonso, and Markman, 1976). Other factors include community pride; social pressures that create undetermined morale, lack of infrastructure, cultural values that enhance violence, rite of passages by the peer groups and general lack of sensitization from relevant Government authorities (Carter \& McGoldrick, 1998; Gottman, 1994a; Kaslow; 1996; Rutter, 1998; Treadway, 1989) eventually enhance the evil practice.

\section{Gender issue and Cattle rustling activities:}

Boys grow up and they graduate to adulthood knowing that they should conduct stock theft to keep the communities ego at high level. Bear in mind that one of the driving force enabling cattle rustling is community's pride. Besides, peer group as a driving force, issues to do with dowry for pride price payment do compel the young men to participate in the evil activity. Girls also graduate to adult hood knowing that the men have to work hard to meet their day to day economic needs. This prevailing situation obviously creates an enabling environment of cattle rustling to take place.

As it stands now, until such a time when all these issues are erased from their respective minds, the evil practice will continue going on. (McGoldrick, Giordano \& Pearce, 1996; miller 1999; parks, Laungani \& young, 1997; Tatelbaum, 1980; Staudacher, 1987; 1991).

\section{Economic Stability and Taming of Cattle Rustling:}

It has been a desire for every Kenyan to lead a decent life that could assure him of ownership of property and the country itself. Every Kenyan requires a good job and a steady source of income but this is not forthcoming among the Pokot communities. Cattle rustling practice came after a desire adopted by the Pokot Community found it as a source of income to establish the community's economy. The more the animals the Pokot have whether as a Community or Society, the more wealth they claim them to posses. It wouldn't matter whether it is an individual ownership or the societal possestion. What matters is that the community is wealthy. On the other hand, the rustlers 
don't care the method they use in getting the animals. Whether they use force to get or not theirs to make sure they own a large stock of cattle cattle. (Burleaon \& Denton, 1997; Gottman, 1994b; Johnson \& Greenberg, 1994).

Apparently, taming of the cattle rustling practice will depend on the approach used to indicate to the community that they still will remain wealthy even after abandoning the out dated culture. Non Governmental Organization have come up with a sensitization programme that it indicates that one can own few livestock and still be wealthy by feeding them well to attract good market price but still it has follen on deaf ears. Education on the other hand will help the children within the community to get a job and use it acquire more livestock other through stock theft. Other means could be by religion. Religious people do at all costs all they could to stay away from anti social behavior like stock theft but still afew come out of the religious community and involve themselves in the practice due cultural preservation (Ahrons, 2004; Ganong \& Coleman, 1989; Kerr \&Bowen, 1988; O'Leary, Heyman, \& Jongsman, 1998).

\section{Communication and Conflict Resolution :}

The Catholic Church through her NGO called "the underpowered" has all along tried to provide a platform of Communication and Conflict Resolution. It has turned to be efficient at village level other than at Divisional administrative position. This explains that it has not been successful at the District level because of the mechanism employed. Ideally, the expected outcome could emante from national level and be cascaded all the way to Village level where the Village Elders will help to administer the necessary standing orders. The Government is to look for ways and means of supporting NGOs with such agendas like Conflict Resolution. As it stands now, NGOs or bodies of the likeminded are like a drop in the ocean. What is required more is for them to help the respective communities realize the intended goals.

\section{Professional's Evaluation of Personal Feelings about Cattle Rustling:}

It has been found that the cattle rustling menace is an outdated practice. The Jurists have had court cases that sound more of family disputes rather than be classified as Criminal or Civil cases. Hence the professionals are looking forward to the Government to chip in and streamline some few issues here and there to absolutely eradicate the practice. The respective Parliamentarians in office including the current $12^{\text {th }}$ Parliament have a big role to push for quick disbursement of the famous Equalization fund. This way, provision of social amenities, good infrastructure, will help bridge the gap

\section{Cattle rustling as Economic sustenance:}

Due to the rising way of lifestyle that prices of commodities are changing day by day, cattle rustling have turned to be an opportunity of economic. This has prompted the respective communities to embark on the menace as a way to generate wealth. This is because it is perceived that the more the cattle an individual owns, the more wealth he or she owns. (Parliamentary select committee, on Security 2002). The notion on the wealth basis drives the respective communities to perform cattle rustling as a source of wealth. To discourage the bad practice to go on, His Excellency the president of Kenya Hon Uhuru Kenyatta supported fully the commissioning of Nyumba kumi initiative to help disinter grate the warring communities pride (President Uhuru on Nyumba Kumi initiative 2010).

\section{Individual Perception:}

When all prevailing issues are well addressed well, an individual perception from civilised or uncivilised point of view can be arrived at. From civilised point of view, an individual is expected to explore other alternative ways of economic sustenance. After being educated, an individual is left with so many option of economic sustenance. For the uncivilised, it the duty of the Government and the community at large is to explore ways to avoid the outdated cattle rustling menace. There are so many ways to sensitize the respective communities on the several ways to abandon the out dated evil practice.

\section{Nomadic Life:}

Conclusively, cattle rustling activities take place because of scores of factors and when such factors are well attended by the Government of the day, it will be easy for the responsible administration to eradicate the menace and the Society calms down to development matters. The marginalized communities will be able to catch up with the develop ones promptly. 


\section{Communities respective participation:}

In Alale-Kacheliba-Kapenguria in West Pokot County, the Pokots as a community have sought of ways to eradicate cattle rustling menace. They have teamed up with civil societies to engage income generation other than participating in the outdated menace. Some of the people have engaged in mining of alluvial gold, Lord Augury is irrigation scheme has absorbed some of the people a s casual/permanent laborers and provision of electricity has turned some of the to be jua kali artisans

In the same region, gender duties have been well defined. Security duties have been provided by Men, while women have to participate in the daytime duties. This has enabled every family to get something on the table besides school fees for school going children. Community's participation has provided a paradigm shift from the cattle rustling to a better way of generating income.

Now, as you noticed provision of electricity has changed community's lifestyle, the government and the civil societies should strife hard to provide more of the tertiary level of education to help them at least apply any kind of knowledge acquired especially through technical schools

\section{Community Violence:}

Community violence arises when everything in existence is articulated in a violent manner. Apparently when cattle rustling takes place, gun shots are heard when a bullet is extended. This affects the new born, the aged and the disabled groups. Harassing them is in itself a violent behavior. It is until such time when this dealt away with is when we can term the community as non violent.

When all these groups are interrogated, the end results suggest that we need to adopt a non violent culture for the growth of a better economy which has no violence in them. Further provision of guiding and counseling technique reinstates the ability to achieve peace so easily unlike before when violent atmosphere reined in the air on daily basis.

\section{Cattle Rustling:}

Cattle rustling comes in strongly several factors are in place. It's an outdated practiced in a shy manner. None of the civilized member of the community would want to be associated with. It's a do or die game in a manner that when one chooses he won't be sure that he will be back from the mission. Some of the effects of that happen as a result of the menace include;

Cattle rustling causes trauma to the affected community. It adversely affects the young, Elderly and the disabled group. When the menace takes place, community affected will have to report to the warriors who will in turn appear in their jungle war gear and eventually cause mayhem to the community.

Some economic activities will come to a standstill as priority will be given to pursuance of the stolen livestock. Business will not be as usual since concerted effort to see how to get back the stolen animals will be the task of the day.

School going Children will adversely affected as some young bys may want to be morans and be part of those pursuing the stolen.

\section{Cattle Rustling Engagement:}

Cattle Rustling engagement automatically comes in as primitive way of obtaining wealth. While on the other hand, it comes as the only alternative to a source of wealth to the pastoralist communities after being marginalized by the respective successive governments. Once the underlying issues are resolved, the menace will be attended to fully and some standing orders may be observed to the latter. In law, much that doesn't pronounce Criminal or Civil Law may not be established as being lawlessness. The resultant issue should use conflict resolution as an amicable methodology to rectify the situation. It's outstanding that civil societies of recent are also researching on better ways to help the Pastoralist communities eradicate the menace. If only the Government of the day manage to direct more resources to these communities, certainty of eradicating the menace within a short time will be experienced. Lawlessness in terms possessing small fire arms also if dealt with to the root cause will bring down engagement on cattle rustling. Availability of replenishment say for consumables like the cartridges, bullets serviceability state of the fire arms when stopped and no more supply is done then a winning formula will have been attained. 


\section{Theoretical Perspective on cattle rustling:}

Cattle rustling have been like a reserve of the Pastoralists. It's because of the ability to handle these animals unlike pedigree animals. These animals are known to run very fast and manage to cover a big distance for those who want to pursue them to either give up get more challenges. It has been establish also that the animals are very hardy. This is to indicate that even in a very harsh weather; they will be able to endure hot whether etc. When in search of green pasture, these animals can go without water for longer period in which case they cannot be compared with the exotic animals which quickly die in case they receive tender care. In as much as the traditional of handling livestock is not attained, the pastoralist will lag behind in every aspect of life.

\section{Research Design and Methodology:- Introduction:}

This chapter discusses the following aspects of research methodology: target population, sample design and sampling technique, research instrument and data collection procedures.

\section{Research design:}

The basic method of this research will be case study, in order to get in-depth information and the data collection instruments that will be used shall be questionnaires, interviews and documentary sources of information. The study targeted Alale-Kacheliba-Kapenguria in West Pokot County that has a population of about 7,000 (as per 1989 pop census) and an area of above 401sq km. (Lands, 1989 and Kenya 1996) comparators it has a small population that could be well served. As a result of boundary changes, the population is relative rural. The population is divided as follows:

$\begin{array}{lcc}\text { Location } & \text { Target population } & \text { Sample size (30\% of population) } \\ \text { Alale } & 4,566 & 1369.8 \\ \text { Kodich } & 5,421 & 1626.3 \\ \text { Amakuriat } & 6,681 & 2004.3 \\ \text { Katikomol } & 9,792 & 2937.6\end{array}$

\section{Ministry of planning (2010) census:}

The town was divided in such a way that the western region with relatively hilly areas was well settled and it acts as a security area for some of the the members of the communities. The Pokot and any other Pastoralist communities chose hilly areas to enable the have a quick view of the approaching enemy whose mission is on cattle rustling. Kacheliba trading center for this case is neighboring a conservancy hence making it a tourism attraction site.

\section{Sampling techniques and Procedures:}

Cluster sampling technique was applied in collecting data from the target population. A cluster samples size of $1 \%$ was selected out of the total population the reason being that the population was too big and the time factor was highly considered. The researcher selected 987 people who were used as a sample size by making a list of their gender and their possibility of criminal profiling. Sampling for the case of cattle rustling was designed to easily discover the ability of pastoral society which do move from point to point in search of pastures for their livestock

The reason to adopt the cluster sampling technique method is because it was easy to obtain detailed information from a sample as compared to an appropriate population. Sampling design was to disfavour the trend of the respective degree of criminality thereby giving a real picture of the prevailing situation. West Pokot for this case is a semi arid geographical area in which case a season varies from one to the other This information can easily be tabulated and analyzed within a very short time and it involves low cost and also saves time.

\section{Research Instruments: Questionnaire:}

The questionnaire was used and data collected by both open and closed ended questions. The individuals were given the questionnaire to provide relevant data. The Questionnaires were justifed because the data were easily analyzed especially from closed ended questions. The researcher did not need to be present when the questionnaires were being filled though it was important to administer the questionnaires personally so as to attend to any difficulty issues that could raise biasness when the respondents were filling the questioners. 


\section{Interview Schedule:}

The interview was used to collect data from the residents of the respective trading centers. The interview schedule consisted of open and closed ended questions based on the objectives of the study.

The justification for interview schedule is that it takes short time especially if the questions are short it also allows the interviewer to clarify the questions since the researcher administers the interview personally. The researcher can easily obtain the intended information by asking objective questions.

\section{Data Collection procedure:}

The researcher identified the sample and informed them on the date and time when the research study was to be carried out. The researcher gave assurance to the participants on the confidential information which enhanced smooth collection of data with minimum suspicion.

The researcher will administered questionnaires and conducted interviews personally to the collected sample of individual. The researcher will also assist them through the filling of questionnaires and the recording of relevant information.

\section{Data Analysis Procedures:}

The data collected was coded, edited for completeness, tabulated and then analyzed both quantitatively and qualitatively to answer the research questions. The data was analyzed using frequency tables, percentages, measures of central tendency, and pie charts. All these procedures will enable the researcher to make comparison and draw valid conclusion. For the case of this undertaking, cattle rustling undergo a varying trend of criminality depending on the seasons of the year on annual basis.

The chapters brought out the main findings of the study to answer research objective, questions and recommend that needs to be done to improve on factors prevailing to enable cattle rustling activities .

\section{Discussions and Findings:}

The whole of West Pokot County has minimal and poor roads and Communication Networks. When the law enforcers are sent to apprehend livestock stolen, they face a lot of challenges in articulating this but very important exercise. The terrain is extremely difficult to venture to make criminal activities be undertaken with ease. The county has only one tarmac road running through a small section leaving and so the same road is growing old as it has several pot holes. The road was built early 70s by the then National Government. The access roads are neither maintained nor worked upon by the required authority. Every annual rain fall through soil erosion destroys the road coverage every year. On the other hand, communication networks are unreliable to the extent that criminal activities take place and they go unreported. The communication equipment especially those that depend on online of sight technique fail because of the rough terrains and the several interlocking spurs of the hilly areas. Safaricom, Airtel and Orange service providers should be encouraged by the national government to establish good communications networks in this county to bring down crime rate.

The study established that the distribution of male and female within Masol-Sigor -Kapenguria in West Pokot County were almost equal ratio of female to male respondents residents in which male represented $49.9 \%$ while female $50.1 \%$. It was found out that the level of education of respondents in the research area was pathetic. The study showed that the level of Education $40 \%$ was at primary level and 31\% at secondary level and 26\% from Tertiary level and 3\% degree holders. This prevailing situation however explains why criminal activities may be combated easily. However, it is hypothesized that devolution might bring some changes that will be productive to the Pokot community. Great expectations are pegged on the government subsidy awarded to every student attending secondary school education this might increase the level of Education respectively and student enrollment in every aspect including the Adult Education department. It was also established that the economic factors influenced stability in marriage. The study showed that economic factors 30\% income influences life stability and $26 \%$ unemployment led to youth cattle rustling, $4 \%$ Community pride influence and $40 \%$ infrastructure influence. The study established that poverty, trauma, financial incapacitation and insecurity had rendered the Pokot community into desperate life

\section{Conclusion and recommendations:-}

Stability in respective societies plays a major role in uplifting economic standards of many people amongst many societies. 
1. The Government should step in to provide social amenities and other centers of excellence which will help stabilize stability in respective communities and make engaged on economic activities.

2. The Government should establish a good infrastructure for the law enforcers to access and assist curb crime promptly. Equalization fund should be availed to help bring at par the communities that were marginalized. Nyumba kumi initiative should be supported fully. The initiative has been found to be very instrumental and can easily assist to curb crimes efficiently.

3. The carriage of the usual weapons by some of the community youth should be discouraged through village elders Barazas for smooth harmonious relationship.

4. The security personnel and administrators in large number should cme from dierent communities.

\section{Reference:-}

1. Berger (1998). Integrative Criminology (International Library of criminology, Criminal Justice and penology). Aldershot/Dartmouth.

2. Berndt \& Survin-William (1990). "Understanding Criminology in current theoretical debates", Burmingham University press

3. Burleon \& Danton (1997) "A Critique of Marxist Criminology."Crime and Justice. Vol. 2 (1980). JSTR. 169

4. Cessare Lombrosso (1835-1901). Of Crimes and Criminals". In Mugure, Mike \& Morgan. The Oxford Handbook of Criminology, $3^{\text {rd }}$ ed. xfrd University Press. 27.Staudacher (1987-91)

5. General Daudi Tonje (Rtd) (2002), Scial surce f deligency. University of Chicago press

6. Giordano, Pearce \& McGoldrick (1996) "The Optimum Enforcement of Laws". In Journal of political Economy, Vol. 78(3), May-June 1970, P 526-536

7. Gottman (1976 ) "Surveillance and Criminal statistics; Historical Foundations of Government. pp 149-184 studies in Law, politics and society, vol. 17, ed. by Austin and Susan. Greenwich, CT: JAI Press.

8. Johnson \& Greenberg (1994), Biosocial Criminology, Chapter one in the Ashagate research companion to Biosocial theories f Crime 2011. Ashagate.

9. Lombrosso-Ferrero (1872), Criminology, $18^{\text {th }}$ ed. Thmson -Wadswrth. P. 139

10. Minuchin and Nichols (1993) "A Critique of Marxist Criminology. "Crime and Justice. Vol. (1980). JSTOR. 165

11. President Uhuru Kenyatta (Republic of Kenya 2015). "Security Management beefed". 